\title{
Constraints on mechanisms and rates of anaerobic oxidation of methane by microbial consortia: process-based modeling of ANME-2 archaea and sulfate reducing bacteria interactions
}

\author{
B. Orcutt ${ }^{1,2}$ and C. Meile ${ }^{1}$ \\ ${ }^{1}$ Department of Marine Sciences, University of Georgia, Athens, GA 30602 , USA \\ ${ }^{2}$ Marine Environmental Biology Section, University of Southern California, Los Angeles, CA 90089 , USA
}

Received: 7 April 2008 - Published in Biogeosciences Discuss.: 9 May 2008

Revised: 23 September 2008 - Accepted: 26 September 2008 - Published: 24 November 2008

\begin{abstract}
Anaerobic oxidation of methane (AOM) is the main process responsible for the removal of methane generated in Earth's marine subsurface environments. However, the biochemical mechanism of AOM remains elusive. By explicitly resolving the observed spatial arrangement of methanotrophic archaea and sulfate reducing bacteria found in consortia mediating AOM, potential intermediates involved in the electron transfer between the methane oxidizing and sulfate reducing partners were investigated via a consortium-scale reaction transport model that integrates the effect of diffusional transport with thermodynamic and kinetic controls on microbial activity. Model simulations were used to assess the impact of poorly constrained microbial characteristics such as minimum energy requirements to sustain metabolism and cell specific rates. The role of environmental conditions such as the influence of methane levels on the feasibility of $\mathrm{H}_{2}$, formate and acetate as intermediate species, and the impact of the abundance of intermediate species on pathway reversal were examined. The results show that higher production rates of intermediates via AOM lead to increased diffusive fluxes from the methane oxidizing archaea to sulfate reducing bacteria, but the build-up of the exchangeable species can cause the energy yield of AOM to drop below that required for ATP production. Comparison to data from laboratory experiments shows that under the experimental conditions of Nauhaus et al. (2007), none of the potential intermediates considered here is able to support metabolic activity matching the measured rates.
\end{abstract}

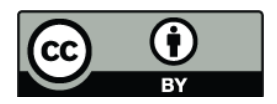

Correspondence to: C. Meile (cmeile@uga.edu)

\section{Introduction}

Methane, a potent greenhouse gas, is produced in anoxic regions of the ocean's subsurface and is largely prevented from entering the overlying water column and reaching the atmosphere by the activity of microorganisms living in marine sediments. Geochemical evidence indicates that the net consumption of methane $\left(\mathrm{CH}_{4}\right)$ in these anoxic environments is linked to the consumption of sulfate $\left(\mathrm{SO}_{4}^{2-}\right.$; Barnes and Goldberg, 1976; Devol et al., 1984; Hoehler et al., 1994; Iversen and Jørgensen, 1985; Reeburgh, 1976):

$\mathrm{CH}_{4}+\mathrm{SO}_{4}^{2-} \rightarrow \mathrm{HS}^{-}+\mathrm{HCO}_{3}^{-}+\mathrm{H}_{2} \mathrm{O}$

Results from DNA- and lipid-based investigations are suggestive of consumption of sulfate and methane that is mediated via a syntrophic relationship between sulfate-reducing bacteria (SRB) and methanotrophic archaea (ANME, after ANaerobic MEthanotroph; Hinrichs et al., 1999). Three distinct phylogenetic clades of ANMEs (ANME-1, -2, and -3; Knittel et al., 2005) and multiple SRB groups (Knittel et al., 2003) have been identified which may be involved with this process.

To date, significant gaps remain in understanding the biochemical mechanism of anaerobic oxidation of methane (AOM), including how the processes of AOM and sulfate reduction (SR) are linked to one another (Hoehler et al., 1994; Nauhaus et al., 2002; Sørensen et al., 2001; Valentine and Reeburgh, 2000). The concentrations of potential intermediates (Table 1) involved in electron exchange, produced during methane oxidation and consumed during sulfate reduction, likely play a significant role in regulating consortium energetics, as high concentrations thermodynamically favor SR but lower the energy yield for the ANME. Thus, a consortium relying on these two processes for energy production

Published by Copernicus Publications on behalf of the European Geosciences Union. 
Table 1. Potential coupled reactions of AOM and SR discussed in Sørensen et al. (2001) and Valentine and Reeburgh (2000), and the corresponding standard free energy yield of the reactions, estimated using data from Stumm and Morgan (1981).

\begin{tabular}{lr}
\hline Reaction couples & $\Delta G^{0}\left(\mathrm{~kJ} \mathrm{~mol}^{-1}\right)$ \\
\hline Hydrogen transfer & \\
$\mathrm{CH}_{4}+3 \mathrm{H}_{2} \mathrm{O} \rightarrow \mathrm{HCO}_{3}^{-}+\mathrm{H}^{+}+4 \mathrm{H}_{2}$ & 229.1 \\
$\mathrm{SO}_{4}^{2-}+4 \mathrm{H}_{2}+\mathrm{H}^{+} \rightarrow \mathrm{HS}^{-}+4 \mathrm{H}_{2} \mathrm{O}$ & -262.0 \\
\hline Acetate transfer & \\
$\mathrm{CH}_{4}+\mathrm{HCO}_{3}^{-} \rightarrow \mathrm{CH}_{3} \mathrm{COO}^{-}+\mathrm{H}_{2} \mathrm{O}$ & 14.8 \\
$\mathrm{SO}_{4}^{2-}+\mathrm{CH}_{3} \mathrm{COO}^{-} \rightarrow 2 \mathrm{HCO}_{3}^{-}+\mathrm{HS}^{-}$ & -47.7 \\
\hline Formate transfer & \\
$\mathrm{CH}_{4}+3 \mathrm{HCO}_{3}^{-} \rightarrow 4 \mathrm{HCOO}^{-}+\mathrm{H}^{+}+\mathrm{H}_{2} \mathrm{O}$ & 154.0 \\
$\mathrm{SO}_{4}^{2-}+4 \mathrm{HCOO}^{-}+\mathrm{H}^{+} \rightarrow 4 \mathrm{HCO}_{3}^{-}+\mathrm{HS}^{-}$ & -186.9 \\
\hline
\end{tabular}

can only function within a certain range of concentrations of the intermediate compound, unless production and consumption are spatially separated enough to allow for a sufficient concentration difference between regions of active AOM and SR. Based on free energy yields in a setting with diffusive exchange of intermediates between an ANME and a nearby SRB cell, Sørensen et al. (2001) suggested that hydrogen and acetate are not feasible intermediates at low methane concentrations (tens of $\mu \mathrm{M}$, representative of shallow water sediment environments). Arguing for lower in situ maintenance energy requirements of the consortia than those considered by Sørensen et al. (2001), Strous and Jetten (2004) determined that acetate is a thermodynamically favorable intermediate in settings with abundant methane $(>10 \mathrm{mM})$, such as $\mathrm{CH}_{4}$ seep environments, while exchange of formate is thermodynamically feasible at lower methane concentrations.

Knowledge of the biochemical mechanism of AOM is limited since attempts to isolate these microorganisms in culture have so far been unsuccessful (Nauhaus et al., 2002). Nonetheless, some clues about the kinetic properties of the process can be derived from studies with environmental samples enriched in AOM-mediating microbes. For instance, cell specific rates of AOM can be inferred by comparing measurements of AOM activity in bulk samples with the corresponding abundance of cells assumed to be responsible for the process. Cell specific rates of AOM on the order of $10^{-4}$ to $10 \mathrm{fmol}$ methane oxidized cell ${ }^{-1} \mathrm{~d}^{-1}$ can be inferred from a variety of datasets (Girguis et al., 2003, 2005; Knittel et al., 2005; Nauhaus et al., 2002; Orcutt et al., 2005); similarly, cell specific rates of SR in the environment are estimated to range from $10^{-2}$ to $10 \mathrm{fmol}$ sulfate reduced cell ${ }^{-1} \mathrm{~d}^{-1}$ (as reviewed in Neretin et al., 2007).
Here we re-evaluate thermodynamic and kinetic constraints on the functioning of an ANME-2/SRB consortium by modeling the distribution of the chemical species involved in $\mathrm{AOM}$ at the scale of the consortium $(<25 \mu \mathrm{m})$, including a number of substances that have been hypothesized to be exchanged between the ANME and the SRB. Three factors potentially govern the sustained rate of methane oxidation in a consortium: (1) the availability of substrate, where high reactant concentrations favor the reaction kinetically; (2) the energy yield of the reaction, where low product concentrations favor the reaction; and (3) the efficiency of transport of the exchangeable species from the zone of AOM (where it is produced) to the SRB (where it is consumed). By resolving the spatial arrangement of the methane oxidizing archaea and the sulfate reducing bacteria in the microbial aggregate, and by explicitly taking into account transport, reaction kinetics and thermodynamic constraints, we expand on and refine a previous assessment of requirements associated with intercellular exchanges by Sørensen et al. (2001), and a recent bulk analysis by Dale et al. (2006). We systematically vary poorly constrained parameters and assess the resulting process rates per aggregate. Specifically, we (i) study the impact of diffusion on the overall process energetics for aggregates of different sizes; (ii) assess the role of minimum energy requirements for the functioning of the consortia; (iii) investigate the thermodynamic feasibility of a number of proposed intermediates; and (iv) consider thermodynamic constraints and the potential for a pathway reversal of the archaea under a variety of environmental conditions. These intrinsic microbial factors are discussed in the context of different environmental settings, in particular methane concentrations. Finally, model results at the consortium scale are compared with available laboratory rate data measured in ANME-2/SRB consortia enriched from a Hydrate Ridge methane seep (Nauhaus et al., 2007). We estimate maximum process rates per aggregate, and assess the likelihood for the different intermediates to give rise to the observed rates.

\section{Model implementation}

\subsection{Consortium arrangement}

While a variety of spatial arrangements of the syntrophic partners have been described (Knittel et al., 2005; Orphan et al., 2001, 2002), one of the predominant AOM-mediating ANME/SRB consortia is found in a spherical arrangement in which SRB form a shell around an inner core of archaea belonging to the ANME-2 cluster, presumably spatially separating SR from AOM (Fig. 1). From a survey on "shell-type" consortia sizes, cell sizes, and ANME:SRB abundance ratios, which were determined via 16S rRNA-based fluorescence in situ hybridization methods (Boetius et al., 2000; Knittel et al., 2003, 2005; Nauhaus et al., 2007; Orphan et al., 2001), a few trends emerge (Table 2). First, ANME-2 and SRB cells 
Table 2. Survey of available data on AOM/SR-mediating consortia sizes, cell sizes, and cell numbers.

\begin{tabular}{|c|c|c|c|c|c|c|c|c|c|}
\hline $\begin{array}{l}\text { Consortia } \\
\text { diameter }^{\mathrm{a}} \\
(\mu \mathrm{m})\end{array}$ & $\begin{array}{r}\text { Inner core } \\
\text { diameter } \\
(\mu \mathrm{m})\end{array}$ & $\begin{array}{l}\text { Layers of } \\
\text { SRB in } \\
\text { outer shell }^{\text {b }}\end{array}$ & $\begin{array}{l}\text { Outer shell } \\
\text { width }^{\mathrm{a}}(\mu \mathrm{m})\end{array}$ & $\begin{array}{l}\text { ANME cell } \\
\text { diameter }^{\mathrm{a}} \\
(\mu \mathrm{m})\end{array}$ & $\begin{array}{l}\text { SRB cell } \\
\text { diameter }^{\mathrm{a}} \\
(\mu \mathrm{m})\end{array}$ & $\begin{array}{r}\text { \# ANME } \\
\text { cells in } \\
\text { aggregate }^{\mathrm{c}}\end{array}$ & $\begin{array}{r}\text { \# SRB } \\
\text { cells in } \\
\text { aggregate }^{\mathrm{c}}\end{array}$ & $\begin{array}{l}\text { SRB: } \\
\text { ANME } \\
\text { ratio }\end{array}$ & Ref. \\
\hline 3 & 2.2 & 1 & 0.4 & 0.5 & 0.4 & 63 & 189 & 3 & A \\
\hline 6 & 4.4 & 2 & 0.8 & 0.5 & 0.4 & 504 & 1513 & 3 & A \\
\hline 12 & 8.8 & 4 & 1.6 & 0.5 & 0.4 & 4034 & 12100 & 3 & A \\
\hline 18 & 13.2 & 6 & 2.4 & 0.5 & 0.4 & 13616 & 40839 & 3 & A \\
\hline 25 & 18.6 & 8 & 3.2 & 0.5 & 0.4 & 38094 & 106261 & 3 & A \\
\hline 7.6 & 5.6 & 2.5 & 1 & 0.5 & 0.4 & 1040 & 3045 & 2.9 & B \\
\hline 3.2 & 2.3 & $\sim 1$ & 0.45 & 0.5 & 0.4 & 72 & 238 & 3.3 & $\mathrm{C}$ \\
\hline
\end{tabular}

A: Nauhaus et al. (2007); B: Knittel et al. (2005); C: Boetius et al. (2000).

a measured via microscopy.

$\mathrm{b}$ derived by dividing the thickness of the SRB shell by the measured average diameter of a SRB cell.

${ }^{\mathrm{c}}$ derived by dividing the volume of an aggregate by the volume of a cell, assuming spherically shaped cells $\left(r_{\mathrm{ANME}}=0.25 \mu \mathrm{m}, r_{\mathrm{SRB}}=0.2 \mu \mathrm{m}\right)$ and densest spherical packing.

identified in these consortia tend to be 0.5 and $0.4 \mu \mathrm{m}$ in diameter, respectively. Second, the ratio of the radius of the zone of ANME to the entire aggregate remains close to 0.73 . Dividing the shell volumes by the respective average cell volumes leads to 3 SRB cells for every 1 ANME cell.

The model represents an individual aggregate, placed into an environment of radius $r_{\text {env }}$ set to at least twice the aggregate radius (Fig. 1). When known, concentrations are imposed at the outer edge of the model domain consisting of the aggregate and its surroundings (Table 3). Alternatively, if the activity of the consortia determines the concentration of a chemical in the surrounding environment, it is assumed that the concentration gradient approaches zero at the domain boundary, as may be the case for the exchangeable species. In the computational model, the physical three-dimensional spherical setting is represented by a quadrant of a circle (Fig. 1) and by imposing rotational symmetry at the vertical coordinate axis and mirroring the resulting half sphere on the horizontal plane. Due to slow observed growth rates, with doubling times on the order of 6 months (Nauhaus et al., 2007), potential changes in aggregate size due to growth are not taken into account.

\subsection{Governing equations}

The concentrations of dissolved chemical species $\left(C_{i}\right)$ are subject to diffusion within the free fluid fraction of the consortium, and production/consumption reactions:

$\phi \frac{\partial C_{i}}{\partial t}=\nabla \cdot\left(\phi D_{i} \nabla C_{i}\right)+\phi R_{i}$

where $t$ is time, $\phi$ is porosity which is set to 0.3 within the consortium - a value slightly above that for densest packing of spherical cells (0.26; Martin et al., 1997) - and 1 in the surrounding pore water, $D_{i}$ is the in situ diffusion coefficient, and $R_{i}$ equals the net of production and consumption

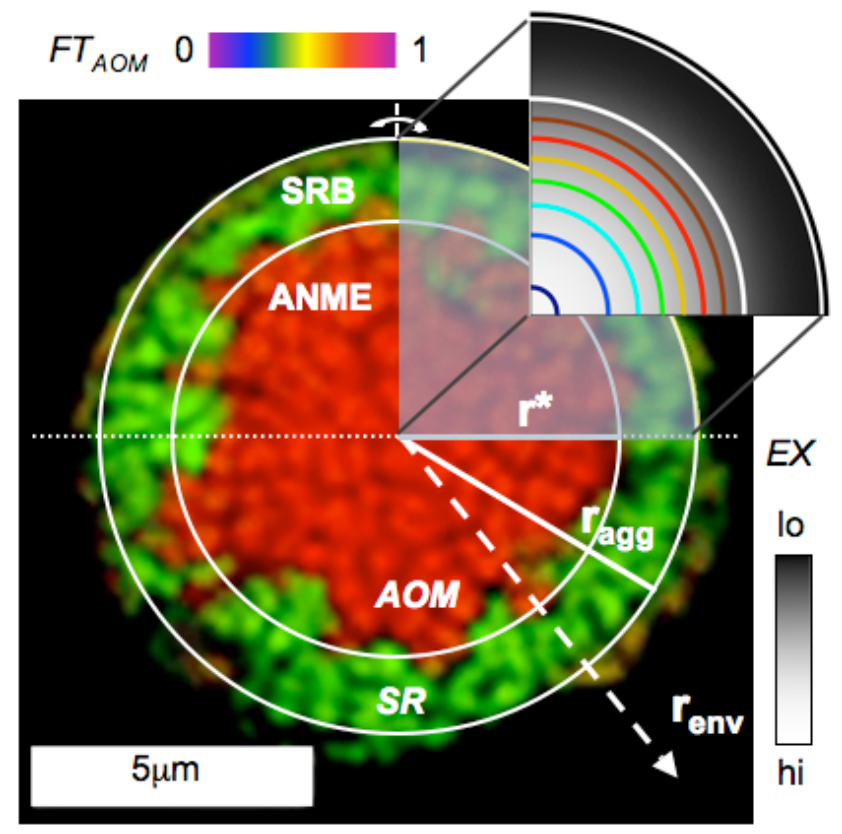

Fig. 1. AOM and SR mediating consortia, modified from Orphan et al. (2002). ANME (center, red) and SRB (shell, green) consortium from Eel River Basin methane-seep sediments surrounded by a layer of exopolymeric saccharide (yellow). The modeled geometrical arrangement is indicated by the white circles. The upper shaded quadrant denotes the model domain (with an inner ANME core radius $r^{*}$, an outer radius of the aggregate $r_{\text {agg and an environmental }}$ radius $r_{\text {env }}$ ), employing axial symmetry around the vertical axis, mirrored on the horizontal midsection plane denoted by the dotted horizontal line. The added quadrant exemplifies a typical model result, with the concentration of the exchangeable species indicated by the gray scale and the value of $F_{T-\text { AOM }}$ denoted by the contour lines. 
Table 3. Properties of compounds considered in the model.

\begin{tabular}{llrll}
\hline Compound & $\begin{array}{l}D_{\mathrm{aq}}^{\mathrm{a}} \\
\mathrm{cm}^{2} \mathrm{~d}^{-1}\end{array}$ & $\begin{array}{r}\Delta G_{f}^{\mathrm{b}} \\
\mathrm{kJ} \mathrm{mol}^{-1}\end{array}$ & $\begin{array}{l}\text { Activitiy } \\
\text { coeff. }^{\mathrm{c}}\end{array}$ & $\begin{array}{l}\text { Boundary value } \\
\mathrm{mM}\end{array}$ \\
\hline $\mathrm{H}_{2}$ & 2.272 & 17.55 & 1 & $10^{-6}-3 \times 10^{-4}$ \\
$\mathrm{HCO}_{3}^{-}$ & 0.593 & -586.9 & 0.642 & 2 \\
$\mathrm{CH}_{4}$ & 0.860 & -34.4 & 1 & $1,19,100$ \\
$\mathrm{HS}^{-}$ & 1.026 & 12.1 & 0.604 & 1 \\
$\mathrm{HCOO}^{-}$ & 0.424 & -351 & 0.604 & $10^{-6}-3 \times 10^{-4}$ \\
$\mathrm{CH}_{3} \mathrm{COO}^{-}$ & 0.552 & -369.4 & 0.642 & $10^{-6}-3 \times 10^{-4}$ \\
$\mathrm{SO}_{4}^{2-}$ & 0.550 & -744.6 & 0.152 & 20 \\
\hline
\end{tabular}

a diffusion coefficients from Schulz (2000).

${ }^{\mathrm{b}}$ Free energy of formation values from Stumm and Morgan (1981). $G_{f}^{0}$ of $\mathrm{H}^{+}$and $\mathrm{H}_{2} \mathrm{O}$ are 0 and $-237.1 \mathrm{~kJ} \mathrm{~mol}^{-1}$, respectively.

$\mathrm{c}$ estimated for an ionic strength of seawater.

$\mathrm{d}$ applicable in imposed concentration simulations; concentrations derived from growth experiments (Nauhaus et al., 2007).

terms of species $i$. Equation (2) is implemented in the finite element simulation environment $\mathrm{COMSOL}^{\circledR}$ and solved for steady state using a direct solver (UMFPACK). The chemical species considered here include methane $\left(\mathrm{CH}_{4}\right)$, dissolved inorganic carbon, sulfide, sulfate $\left(\mathrm{SO}_{4}^{2-}\right)$ and the exchangeable species, (i.e. $\mathrm{H}_{2}$, formate, acetate; Table 1).

Without explicit knowledge of intracellular metabolite levels and cross-membrane transport, metabolite transport in the model is restricted to the extracellular aqueous phase. In situ diffusion coefficients are based on measures of molecular diffusion in dilute solutions at $8^{\circ} \mathrm{C}\left(D_{a q}\right.$, Table 3$)$. Aggregates are typically embedded in a thick organic matrix (Knittel et al., 2005; Orphan et al., 2001). Estimating its effect on diffusion from experiments with extracellular polymers, the diffusion coefficient is reduced by a factor $f_{\text {eps }}$, set to 0.25 for organic ions and to 0.6 for inorganic ions and gases (Stewart, 2003). The presence of cells is taken into account via a tortuosity correction, so that the in situ diffusion coefficient is defined as:

$D=f_{\text {eps }} \frac{D_{\text {aq }}}{\theta^{2}}$

where the tortuosity factor $\theta^{2}$ is set to 2.5 . This is at the lower end of tortuosity values suggested from porositytortuosity datasets (Boudreau, 1997), but leads to values of effective diffusion coefficients at the lower end of the range determined experimentally in microbial mats (Wieland et al., 2001).

\subsection{Reactions and rate laws}

The reactions in AOM and SR zones can be generalized as follows:

$\mathrm{CH}_{4} \rightarrow \mathrm{EX}+\mathrm{HCO}_{3}^{-}$

$\mathrm{SO}_{4}^{2-}+\mathrm{EX} \rightarrow \mathrm{HS}^{-}$

where EX represents the intermediate species which acts as the electron carrier between AOM and SR (Table 1). AOM occurs exclusively within the inner sphere of ANME in the aggregate while SR is restricted to the outer shell of the aggregate. The rate laws contain a Monod-type dependence on the substrates of each reaction and account for environmental conditions via a factor $\left(F_{T}\right)$ that depends on the cell's energy yield:

$$
\begin{aligned}
& R_{\mathrm{AOM}}=k_{\mathrm{AOM}} B_{\mathrm{ANME}} \frac{\left[\mathrm{CH}_{4}\right]}{K m \mathrm{CH}_{4}+\left[\mathrm{CH}_{4}\right]} F_{T-\mathrm{AOM}} \\
& R_{\mathrm{SR}}=k_{\mathrm{SR}} B_{\mathrm{SRB}} \frac{[\mathrm{EX}]}{K m \mathrm{EX}+[\mathrm{EX}]} \frac{\left[\mathrm{SO}_{4}^{2-}\right]}{K m \mathrm{SO}_{4}+\left[\mathrm{SO}_{4}^{2-}\right]} F_{T-\mathrm{SR}}
\end{aligned}
$$

where $R_{\mathrm{AOM}}$ and $R_{\mathrm{SR}}$ are the $\mathrm{AOM}$ and $\mathrm{SR}$ rates, respectively; $k_{\mathrm{AOM}}$ and $k_{\mathrm{SR}}$ are the corresponding cell specific rate constants (fmolcell ${ }^{-1} \mathrm{~d}^{-1}$ ); $B_{\mathrm{ANME}}$ and $B_{\mathrm{SRB}}$ are the cell densities of ANME in the inner core and SRB within the outer shell of the consortium (cells $\mathrm{cm}^{-3}$ ), respectively; $\left[C_{i}\right]$ represents the concentration of species $i ; \mathrm{KmCH}_{4}$, $\mathrm{KmEX}$ and $\mathrm{KmSO}_{4}$ are the half-saturation constants for methane, the exchangeable species and sulfate, respectively; and $F_{T-\mathrm{AOM}}$ and $F_{T-\mathrm{SR}}$ are the "thermodynamic potential" factors (Jin and Bethke, 2003, 2007) for AOM and SR, respectively.

Baseline values of various parameters are presented in Table 4. All cells are assumed to have the same maximum turnover potential such that $k_{\mathrm{AOM}}$ and $k_{\mathrm{SR}}$ are population specific constants. A range of $K m \mathrm{EX}$ values leading to zeroth to first order kinetics (Eq. 7) were considered. Half saturation constants for the exchangeable species are assumed to be on the order of typical concentration ranges measured in the environment, as may be the case for SRB adapted to in situ conditions and able to respond to perturbations in substrate availability. For example, $K m \mathrm{H}_{2}$ is varied in the nanomolar range, reflecting measured hydrogen concentrations in or around the zone of AOM and previous estimates of half saturation constants in coastal marine sediments (Hoehler et al., 1994, 1998; Finke, 2003; Dale et al., 2006). $K m$ values for sulfate and methane were chosen to be similar to previous investigations (Dale et al., 2006) and are comparable to values calculated from experimental data (T. Treude and A. Boetius, personal communication). 
Table 4. Model parameters.

\begin{tabular}{lll}
\hline Parameter & Description & Values/Units \\
\hline$K m \mathrm{CH}_{4}$ & Half-saturation constant for methane in AOM & $10 \%$ of $\left[\mathrm{CH}_{4}\right]$ at boundary, $0.1-10 \mathrm{mM}$ \\
$K m \mathrm{EX}$ & Half-saturation constant for exchangeable species in SR & $100 \mathrm{nM}$ \\
$K m \mathrm{SO}_{4}$ & Half-saturation constant for sulfate in SR & $1 \mathrm{mM}$ \\
$R_{\mathrm{AOM}}$ & Rate of AOM & Eq. (6) \\
$R_{\mathrm{SR}}$ & Rate of SR & Eq. (7) \\
$k_{\mathrm{AOM}}$ & Per cell turnover rate of methane by ANME & varied $\mathrm{fmol} \mathrm{cell}^{-1} \mathrm{~d}^{-1}$ \\
$k_{\mathrm{SR}}$ & Per cell turnover rate of sulfate by SRB & varied $^{\mathrm{a}}, \mathrm{fmol} \mathrm{cell}^{-1} \mathrm{~d}^{-1}$ \\
$B_{\mathrm{ANME}}$ & Cell density of ANME in inner core of consortia & $1.1 \times 10^{16} \mathrm{cells}^{-1}$ \\
$B_{\mathrm{SRB}}$ & Cell density of SRB in outer shell of consortia & $2.2 \times 10^{16} \mathrm{cells}^{-1}$ \\
$F_{T-\mathrm{AOM}}$ & Thermodynamic factor of AOM & 0 to $1[-]^{-1}$ \\
$F_{T-\mathrm{SR}}$ & Thermodynamic factor of SR & 0 to $1[-]$ \\
$m \Delta G_{\mathrm{ATP}}$ & Minimum energy threshold & $1-10 \mathrm{~kJ} \mathrm{~mol}^{-1}$ \\
\hline
\end{tabular}

a Estimates for rate constants are obtained from data in Nauhaus et al. (2007), assuming no substrate or thermodynamic limitations; cell specific rate in this experiment result in $k_{\mathrm{AOM}} \sim 0.1-1 \mathrm{fmol} \mathrm{cell}^{-1} \mathrm{~d}^{-1}$ are comparable to estimates from other data sets $\left(10^{-4}\right.$ to $10 \mathrm{fmol} \mathrm{cell}^{-1} \mathrm{~d}^{-1}$; Girguis et al., 2003, 2005; Knittel et al., 2005; Nauhaus et al., 2002; Orcutt et al., 2005).

$\mathrm{b}$ The number of cells within an aggregate was obtained by dividing the volume of the inner core and the outer shell by an estimate of the respective cell volumes and assuming densest even packing (Nauhaus et al., 2007), which resulted in $11.1 \mathrm{cells}^{2} \mu \mathrm{m}^{-3}$ in the inner core and 22.2 cells $\mu \mathrm{m}^{-3}$ in the outer shell, respectively ( $B_{\mathrm{ANME}}$ and $\left.B_{\mathrm{SRB}}\right)$.

The thermodynamic potential factors $\left(F_{T-X}\right.$, where $X$ represents either AOM or SR) reflect that there must be sufficient free energy available from the reactions to fuel ATP synthesis and cell maintenance. For instance, if the concentration of the intermediate species made AOM energetically unfavorable, regardless of the availability of methane for consumption, methane oxidation is assumed not to take place. $F_{T-X}$ is defined as:

$F_{T-X}=\max \left(0,1-\exp \left(\frac{f_{X}}{\chi R_{g} T}\right)\right)$

where $\chi$, the number of ATP synthesized per reaction, equals $1, R_{g}$ is the universal gas constant $\left(8.314 \mathrm{~J} \mathrm{~K}^{-1} \mathrm{~mol}^{-1}\right)$ and $T$ is the absolute temperature $(281.15 \mathrm{~K}) . f_{X}$ represents the thermodynamic driving force for reaction $X$, relating the free energy yield of that reaction to the energy required to synthesize ATP (Jin and Bethke, 2003, 2007) and is determined as:

$f_{X}=-\Delta G_{X}-m \Delta G_{\mathrm{ATP}}$

Here, $\Delta G_{X}$ is the free energy yield of reaction $X$ under in situ conditions, i.e.

$\Delta G_{X}=\Delta G_{X}^{0}+R T \ln \left(\prod a_{i}^{v_{i}}\right)$

$\Delta G_{X}^{0}$ is the standard free energy of reaction, determined from the free energy of formation of the species involved in the reactions (Table 3 ), $a_{i}$ represents the activity of species $i$, computed based on the modeled concentrations and the activity coefficients given in Table 3 , and $v_{i}$ are the stoichiometric coefficients. $m$ in Eq. (9) is the number of ATP synthesized per electron transferred. Direct measurements of $m$ for AOM do not exist, as no pure cultures of AOM-mediating microorganisms can be manipulated for such a study. Available genomic data indicate that AOM may occur via a reversal of the enzymatic process of methanogenesis (Hallam et al., 2003, 2004; Krüger et al., 2003), thus we estimate $m$ based on available data from methanogenic archaea, presented by Deppenmeier (2002). In methanogenesis, the final enzymatic step catalyzed by methyl coenzyme A reductase creates a heterodisulfide of coenzymes B and S. The cleavage of this heterodisulfide by oxidoreductases fuels electron transport in the cell, which is accompanied by proton translocation $\left(4 \mathrm{H}^{+} / 2 \mathrm{e}^{-}\right)$and drives ATP synthesis. Thus, there is 1 ATP synthesized per 2 electrons transported, and $m=\frac{1}{2}$. $m \Delta G_{\mathrm{ATP}}$ in Eq. (9) represents the threshold energy limit for growth, which is often assumed to be the energy required to synthesize ATP. Assuming $\sim 60 \mathrm{~kJ} \mathrm{~mol}^{-1}$ ATP to form ATP from ADP and phosphate and that three protons are translocated per ATP produced (Schink, 1997; Thauer, 1977), this energetic limit is on the order of $20 \mathrm{~kJ} \mathrm{~mol}^{-1} \mathrm{H}^{+}$, though it has been shown experimentally that some methanogens can survive with a free energy yield of $12-16 \mathrm{~kJ} \mathrm{~mol}^{-1} \mathrm{H}^{+}$(Jackson and McInerney, 2002), and even lower threshold energy limits of $4 \mathrm{~kJ} \mathrm{~mol}^{-1} \mathrm{H}^{+}$have been proposed (as reviewed in Dale et al., 2006). In our model, a range of $m \Delta G_{\text {ATP val- }}$ ues from $1-10 \mathrm{~kJ} \mathrm{~mol}^{-1} \mathrm{H}^{+}$is considered. The lower end of this range in particular represents an end-member setting with minimal energetic constraints on cell functioning. Note that Eq. (8) restricts the value of $F_{T-X}$ to the range between 0 and 1 and does not allow for a net back reaction. 


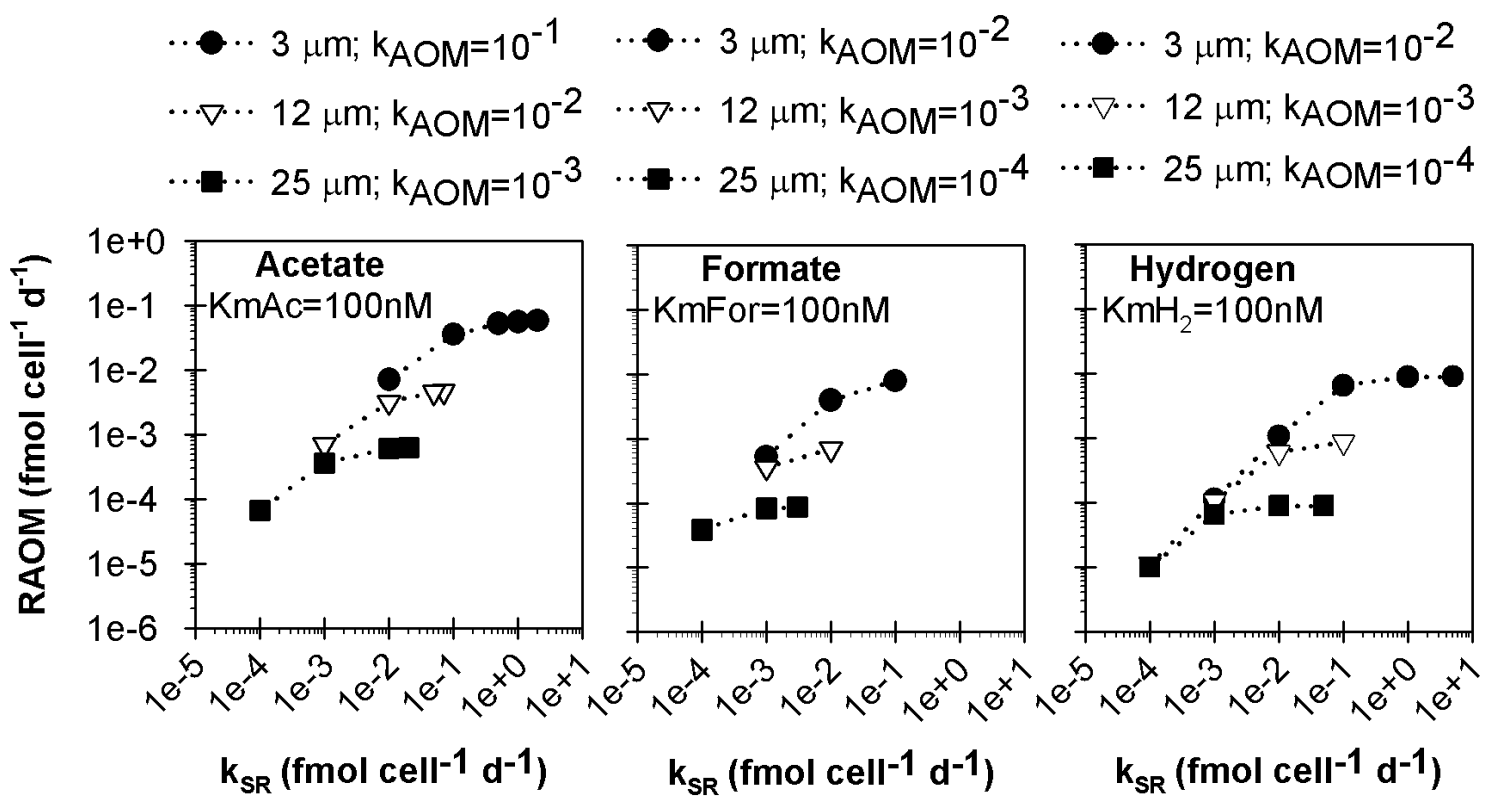

Fig. 2. Maximum rates of AOM calculated for variously sized aggregates $(3,12$ or $25 \mu \mathrm{m}$ OD) with each of the intermediate species acetate, formate, and hydrogen. For all simulations, methane was assumed to be $19 \mathrm{mM}$, the $m \Delta G_{\text {ATP }} 1 \mathrm{~kJ} \mathrm{~mol}^{-1}$ and $K m \mathrm{EX} 100 \mathrm{nM}$. Note the different maximum cell specific AOM rates $\left(k_{\mathrm{AOM}}\right.$, in fmol cell $\left.{ }^{-1} \mathrm{~d}^{-1}\right)$ for each size and intermediate species.

In situ energy yield (Eq. 10) depends on the activities of individual compounds and hence chemical speciation. For a solution containing $\mathrm{Ca}^{2+}, \mathrm{K}^{+}, \mathrm{Mg}^{2+}, \mathrm{Na}^{+}$, $\mathrm{Cl}^{-}, \mathrm{SO}_{4}^{2-}$ at concentrations of seawater, $1 \mathrm{mM}$ sulfide and $2 \mathrm{mM}$ dissolved inorganic carbon, and the potential intermediates acetate and formate present at micromolar levels, the $\mathrm{CH}_{3} \mathrm{COO}^{-}$and $\mathrm{HCOO}^{-}$species constitute more than half the total concentrations over a range of $\mathrm{pH} 5$ to 9 . Though the impact of organics in the intercellular space is not known, simulations in which only a $10 \%$ fraction of the total intermediate concentrations is considered in free form when calculating $F_{T}$ suggest that speciation of the exchangeable species may not be the dominant control on the process energetics (not shown). Variations relevant to the calculation of the in situ $\Delta G_{\mathrm{rxn}}$ result from the relative distribution of the acidbase species $\mathrm{H}_{2} \mathrm{CO}_{3}-\mathrm{HCO}_{3}^{-}-\mathrm{CO}_{3}^{2-}$ and $\mathrm{H}_{2} \mathrm{~S}-\mathrm{HS}^{-}-\mathrm{S}^{2-}$, respectively. Below, we assume a spatially uniform $\mathrm{pH}$ of 8 , so that bicarbonate and hydrogen sulfide are the dominant forms of dissolved inorganic carbon and sulfide.

\section{Results and discussion}

To quantify thermodynamic and kinetic influences on the rates of AOM performed by the ANME/SRB shell-type consortia, model simulations were conducted in which poorly constrained parameters were varied systematically. The results presented focus on the maximum rates of AOM per aggregate that can be achieved in the model for a given environmental setting. The accumulation of the exchangeable species with increasing $k_{\mathrm{AOM}}$ leads to thermodynamic limitation of AOM in the aggregate center. Our simulations consistently indicated much stronger thermodynamic challenges for the ANME compared to the SRB, and the presentation of the results thus highlights controls on $F_{T-\text { AOM }}$ and the rate of AOM.

In the absence of rigorous constraints on reaction rate constants, we only consider model parameterizations that allow for $\mathrm{AOM}$ in a section extending beyond one cell diameter away from the SRB subdomain, and for SR within more than one cell diameter distance from the ANME zone, so that results characterized by drastic changes at or below the scale of individual cells are not included in the analysis.

\subsection{Impact of transport intensity and aggregate size}

Diffusive transport counteracts the build up of the exchangeable species within the inner core of the consortia and provides the SRB with substrate. Given the critical role of transport of the exchangeable species from the location of production to the zone of sulfate reduction, the poorly constrained influence of the organic matrix on diffusive transport was investigated. Removing the impact of EPS on diffusion lessened thermodynamic limitation (i.e. higher $F_{T-\text { AOM }}$ without EPS). However, even for organic ions with a low value of $f_{\text {eps }}$, the magnitude of the change was not large enough to significantly modify the consortia's methane consumption rate (data not shown). 

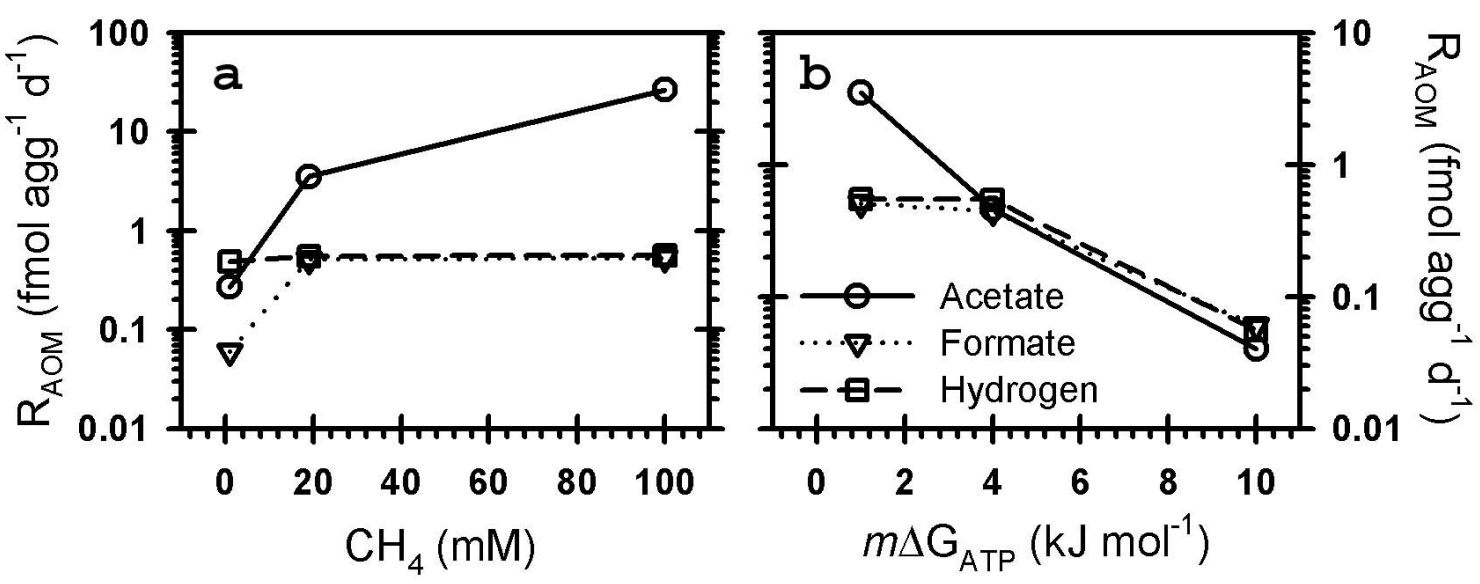

Fig. 3. Maximum rates of AOM per aggregate for each intermediate shown as a function of the methane concentration at the model domain boundary (a) and the thermodynamic threshold (b), assuming a $K m \mathrm{EX}$ of $100 \mathrm{nM}$ for each intermediate. Aggregate size is set to $3 \mu \mathrm{m}$. $k_{\mathrm{AOM}}$ is adjusted to maximize $R_{\mathrm{AOM}}$ under each scenario $\left(k_{\mathrm{AOM}}=0.01-1 \mathrm{fmol} \mathrm{cell}^{-1} \mathrm{~d}^{-1}\right.$ for acetate, $0.001-0.1 \mathrm{fmol}$ cell ${ }^{-1} \mathrm{~d}^{-1}$ for formate, and $0.001-0.1 \mathrm{fmol}$ cell ${ }^{-1} \mathrm{~d}^{-1}$ for hydrogen) and $k_{\mathrm{SR}}$ is roughly one order of magnitude higher than $k_{\mathrm{AOM}}$ (see Fig. 2). Panel a assumes a $m \Delta G_{\mathrm{ATP}}$ of $1 \mathrm{~kJ} \mathrm{~mol}^{-1}$, and panel b a CH 4 concentration of $19 \mathrm{mM}$. Symbols are the same between panels and correspond to the legend shown in panel b; note difference in scales of y-axes.

Aggregates vary in size from a few to tens of micrometers (Table 2), and such a difference in spatial dimension may impact the distribution of chemicals and turnover rates in the consortium. Model simulations show that for a given set of kinetic parameters, aggregate size can significantly affect the magnitude of rates of AOM, with higher rates and lower thermodynamic limitation occurring in the smaller aggregates. For example, Fig. 2 displays the differences in maximum AOM rates for variously sized aggregates $(3,12$ and $25 \mu \mathrm{m}$ consortium diameters) assuming acetate, formate or hydrogen as the exchangeable species. In all cases, the half saturation constant for the exchangeable species was assumed to be $100 \mathrm{nM}$, which corresponds to a value that is $1-100$ times the average concentration at steady state in the inner core of the aggregate. For any given aggregate size and assumed cell specific rate of AOM, the thermodynamic limitation of AOM decreases with increasing cell specific rate of SR, which is reflected in the increasing rate of AOM. For each exchangeable species considered, the maximum cell specific rate of AOM decreases with increasing size of the aggregate, reflecting that AOM becomes energetically less favorable as the consortia grow in size. Additionally, at these cell specific turnover rates, $F_{T-\text { AOM }}$ is homogenous in the smaller consortia, while in the larger ones $F_{T-\mathrm{AOM}}$ shows a pronounced gradient with higher values next to the contact with the SRB shell, as depicted qualitatively in Fig. 1. For consortia larger in size ( 25 vs. 12 and $3 \mu \mathrm{m}$, Fig. 2), some of the areas of production of the exchangeable species are too far away from the SRB; thus, the exchangeable species cannot diffuse out of the inner core fast enough to prevent its build up to a level that lowers the available free energy yield below what is necessary for maintaining cell activity.
In addition to their size, the (possibly patchy) spatial distribution of the aggregates within the sediment matrix may also affect bulk AOM rates. For a typical aggregate density of $10^{7}$ per $\mathrm{cm}^{3}$ (Knittel et al., 2003), aggregates are on the order of 10-100 $\mu \mathrm{m}$ apart, assuming that they are about equally spaced within the environment. $F_{T}$ was found to vary little with the size of $r_{\mathrm{env}}$, even when imposing aggregate distances on the order of $1 \mu \mathrm{m}$, implying a clustered and uneven distribution. Also, when imposing high exchangeable species concentrations - assumed to be maintained by processes external to the aggregates - at the outer domain boundary, $F_{T-\mathrm{AOM}}$ is only slightly diminished (not shown). This indicates that the distribution of aggregates in otherwise homogeneous sediments does not influence the energetics of AOM significantly.

\subsection{Kinetic and thermodynamic controls on reaction rates}

In the absence of experimental data on the nature of the intermediate species of coupled AOM/SR and the associated kinetic parameters, the impact of rate and half saturation constants on AOM activity and thermodynamic limitations was investigated. For each of the three potential intermediates considered, model simulations were run in which the maximum cell specific rates of $\mathrm{AOM}$ and $\mathrm{SR}, k_{\mathrm{AOM}}$ and $k_{\mathrm{SR}}$, were varied. Rates increase with increasing $k_{\mathrm{AOM}}$, until at high $k_{\mathrm{AOM}}$ values diffusion is too slow to prevent build up of products in the zone of AOM, leading to thermodynamic shutdown of the reaction in the center of the aggregate. The value of this maximum cell specific rate of AOM differs between the potential intermediates and depends on the environmental conditions and aggregate size (Figs. 2 and 3). For example, when the methane concentration at the model boundary 
is $19 \mathrm{mM}$ and the thermodynamic threshold is assumed to be $1 \mathrm{~kJ} \mathrm{~mol}^{-1}$, for a $3 \mu \mathrm{m}$ aggregate the highest $k_{\mathrm{AOM}}$ value with acetate is $0.1 \mathrm{fmol} \mathrm{cell}^{-1} \mathrm{~d}^{-1}$ while with formate and hydrogen, $k_{\mathrm{AOM}}$ is limited to $0.01 \mathrm{fmol} \mathrm{cell}^{-1} \mathrm{~d}^{-1}$.

For a fixed value of $k_{\mathrm{AOM}}$, the rate of $\mathrm{AOM}$ increases with increasing cell specific rates of SR (Fig. 2). This is not because of a change in the availability of AOM substrates, but because increasing $k_{\mathrm{SR}}$ promotes depletion of EX, which leads to a more efficient removal and lower levels of EX in the aggregate core. Hence, the increase in $k_{\mathrm{SR}}$ improves thermodynamic favorability of the AOM reaction. This pattern holds until a point is reached in which the rate of SR is too high to be sustained by the delivery via diffusion of the exchangeable species from AOM (Fig. 2).

This upper limit for $k_{\mathrm{SR}}$, as evidenced by the right-hand end of the lines in Fig. 2 extending to higher $k_{\mathrm{SR}}$ at higher $k_{\mathrm{AOM}}$, varies between the considered compounds, which can be explained by the stoichiometry of the AOM/SR reactions and by differences in diffusion coefficients of the intermediate compounds. For example, in a $3 \mu \mathrm{m}$ consortia with a cell specific AOM rate of $0.01 \mathrm{fmolcell}^{-1} \mathrm{~d}^{-1}$, a $m \Delta G_{\text {ATP }}$ of $1 \mathrm{~kJ} \mathrm{~mol}^{-1}$ and a $K m \mathrm{EX}$ of $100 \mathrm{nM}$, the maximum cell specific rate of SR for acetate is approximately $1 \mathrm{fmol}$ cell $^{-1} \mathrm{~d}^{-1}$, whereas for formate the maximum cell specific rate of SR is around $0.1 \mathrm{fmol} \mathrm{cell}^{-1} \mathrm{~d}^{-1}$. The diffusion and activity coefficients of formate and acetate are similar (Table 3), yet for every methane molecule consumed, there are 4 formate molecules produced as opposed to 1 acetate molecule. The higher production of formate per methane can lead to a higher availability of substrate for the $\mathrm{SRB}$, and the reduced substrate limitation increases SR rates at the ANME-SRB interface, causing a narrowing of the SR zone at lower cell specific rates. Hydrogen and formate exhibit the same substrate-to-intermediate stoichiometry (four molecules of intermediate per methane molecule), yet the maximum cell specific rate of SR for hydrogen is higher than for formate at approximately $5 \mathrm{fmol} \mathrm{cell}^{-1} \mathrm{~d}^{-1}$, which can be explained by the higher diffusion coefficient of hydrogen than of formate (Table 3 ).

In the simulations presented here, the half saturation constant for the exchangeable species $(K m \mathrm{EX})$ was assumed to be $100 \mathrm{nM}$, a value which equals or exceeds the average steady state concentration of the exchangeable species within the inner ANME core of the aggregate and in the environment surrounding the aggregate (data not shown). However, similar maximum rates were achieved at higher (up to $1 \mathrm{mM}$ ) and lower (down to $0.1 \mathrm{nM}) K m \mathrm{EX}$ values by varying the cell specific rate of sulfate reduction $\left(k_{\mathrm{SR}}\right)$. Similarly, varying $k_{\text {AOM }}$ allowed balancing the effect of changing $\mathrm{KmCH}_{4}$, which - as $K m \mathrm{EX}$ - is poorly constrained.

Previous examinations of the syntrophic AOM/SR consortia indicate that methane availability may determine which compounds can be feasible electron shuttles, due to the impact that methane concentrations have on the free energy yield of AOM (Sørensen et al., 2001; Strous and Jet- ten, 2004; Valentine, 2002). Acetate, and to some degree hydrogen, have been considered feasible intermediates in the AOM/SR syntrophy at elevated methane concentrations (high $\mathrm{mM}$ range), whereas formate might lead to favorable AOM at lower methane concentrations. As shown in Fig. 3, our simulations indicate that AOM is thermodynamically favorable for all three potential intermediate compounds when the combination of kinetic parameters allows for efficient removal of the exchangeable species from the zone of AOM, and when the assumed energy threshold is relatively low (i.e. $m \Delta G_{\text {ATP }}$ is $1 \mathrm{~kJ} \mathrm{~mol}^{-1}$; see below for further discussion about the impact of varying the energy threshold). Under the range of methane concentrations considered here, the calculated maximum rates of AOM per aggregate are highest when acetate is the intermediate species.

AOM dynamics with acetate as the exchangeable species vary more in relation to changes in methane concentration than is observed for either formate or hydrogen (Fig. 3a). For example, in a $3 \mu \mathrm{m}$ aggregate using acetate as intermediate and with an assumed energy threshold of $1 \mathrm{~kJ} \mathrm{~mol}^{-1}$, maximum AOM rates per aggregate drop by two orders of magnitude with decreasing methane concentration from 100 to $1 \mathrm{mM}$. By comparison, the maximum AOM rates per aggregate using formate or hydrogen only vary by an order of magnitude within the same methane concentration range. With methane concentrations varying little over space, and with $\mathrm{KmCH}_{4}$ values smaller than the methane concentrations, this difference in response of the maximum rate of AOM to methane concentrations can be linked to factors affecting $F_{T-\text { AOM. In }}$. Inciple, as methane concentrations increase, higher cell specific rates of AOM are possible, due to improved thermodynamics of the AOM reaction. However, the larger intermediate-to-substrate stoichiometry in the AOM reaction for hydrogen and formate counteracts this effect more strongly than for acetate. The build-up of intermediates leads to thermodynamic limitation in the aggregate core, causing that the maximum cell specific rate of AOM cannot increase with increasing methane concentration for hydrogen and formate. In addition, the larger diffusion coefficient for hydrogen than for formate allows hydrogen to be removed from the ANME core faster to maintain a relatively high $F_{T-\text { AOM }}$, which explains why it can support a higher rate of AOM than formate at low methane concentrations.

An additional parameter influencing the thermodynamic limitation of AOM is the minimum free energy required to maintain life - the $m \Delta G_{\text {ATP. }}$ The prior examples were calculated with an assumed $m \Delta G_{\text {ATP }}$ of $1 \mathrm{~kJ} \mathrm{~mol}^{-1}$ electron, an exceptionally low value in comparison to typical assumed values that are closer to $20 \mathrm{~kJ} \mathrm{~mol}^{-1}$. Figure $3 \mathrm{~b}$ illustrates the impact of $m \Delta G_{\mathrm{ATP}}$ on the dynamics of AOM for the various intermediate species exchanged by a $3 \mu \mathrm{m}$ consortium under a methane concentration of $19 \mathrm{mM}$. As observed above, the consortia modeled with acetate shows the most pronounced variance with changes in assumed energy requirements - as the energy threshold raises, the thermodynamic favorability 
and subsequent rate of $\mathrm{AOM}$ with acetate decreases significantly. AOM rates based on formate and hydrogen also show pronounced decreases with increasing assumed energy thresholds, with rates dropping by an order of magnitude be-

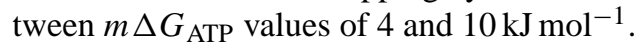

\subsection{What is the exchangeable species?}

To determine which compound(s) can feasibly serve as the exchangeable species in AOM/SR syntrophy, modeled bulk rates of AOM are compared to laboratory results gathered from a growth experiment with ANME-2 - Desulfosarcina/Desulfococcus shell-type consortia, enriched from a Hydrate Ridge methane seep and incubated with abundant $(19 \mathrm{mM})$ methane (Nauhaus et al., 2007). In that experiment, a near ten-fold increase in AOM-mediating community abundance corresponded to a $\sim$ ten-fold increase in the rate of metabolic activity. At the end of the experiment the rate of activity in the enrichment was approximately $230 \mu \mathrm{mol}$ (gram dry sediment, gds) ${ }^{-1} \mathrm{~d}^{-1}$, and the size distribution of the aggregates was recorded (Table 5). To compare model simulations with experimental values, the methane consumption for an aggregate of a given size is computed and then multiplied by the number of aggregates in that size class in 1 gram of sediment at the end of the Nauhaus experiment (Table 5). This approach takes into account the potential for reduced AOM rates in the center of larger aggregate and considers the relative contribution of that size aggregate to the total rate.

Figure 4 shows the maximum bulk rates of AOM calculated for each intermediate (at $19 \mathrm{mM}$ methane and assuming a thermodynamic threshold of $1 \mathrm{~kJ} \mathrm{~mol}^{-1}$ and a half saturation constant for the exchangeable species of $100 \mathrm{nM}$ ) and illustrates the contribution of each aggregate size class to the total rate. For each intermediate, at relatively low cell specific rates of AOM, the larger aggregate size classes contribute the most to the calculated bulk rate of AOM due to higher number of total ANME cells contained in these largersized aggregates. As the cell specific rate of AOM $\left(k_{\mathrm{AOM}}\right)$ increases and thermodynamic limitation prevents activity in the larger aggregates, the smaller aggregates begin to dominate the bulk rate of AOM activity. Indeed, the bulk rates of AOM achieved by the smaller consortia are higher than those possible by the larger aggregates, even though the total number of ANME cells in the smaller consortia is relatively low (Table 5). This indicates that under conditions that lead to energetic constrains in the aggregate center, the smaller sized aggregates may contribute a high proportion of the overall bulk AOM rate.

The above simulations evaluating the effect of the variation of intermediate species and maximum cell specific rates allows one to constrain the parameter space consistent with the Nauhaus observation. For the simulations conducted with $19 \mathrm{mMCH}_{4}$, i.e. the methane concentration used in the Nauhaus experiments, and assuming $1 \mathrm{~kJ} \mathrm{~mol}^{-1} m \Delta G_{\text {ATP }}$,
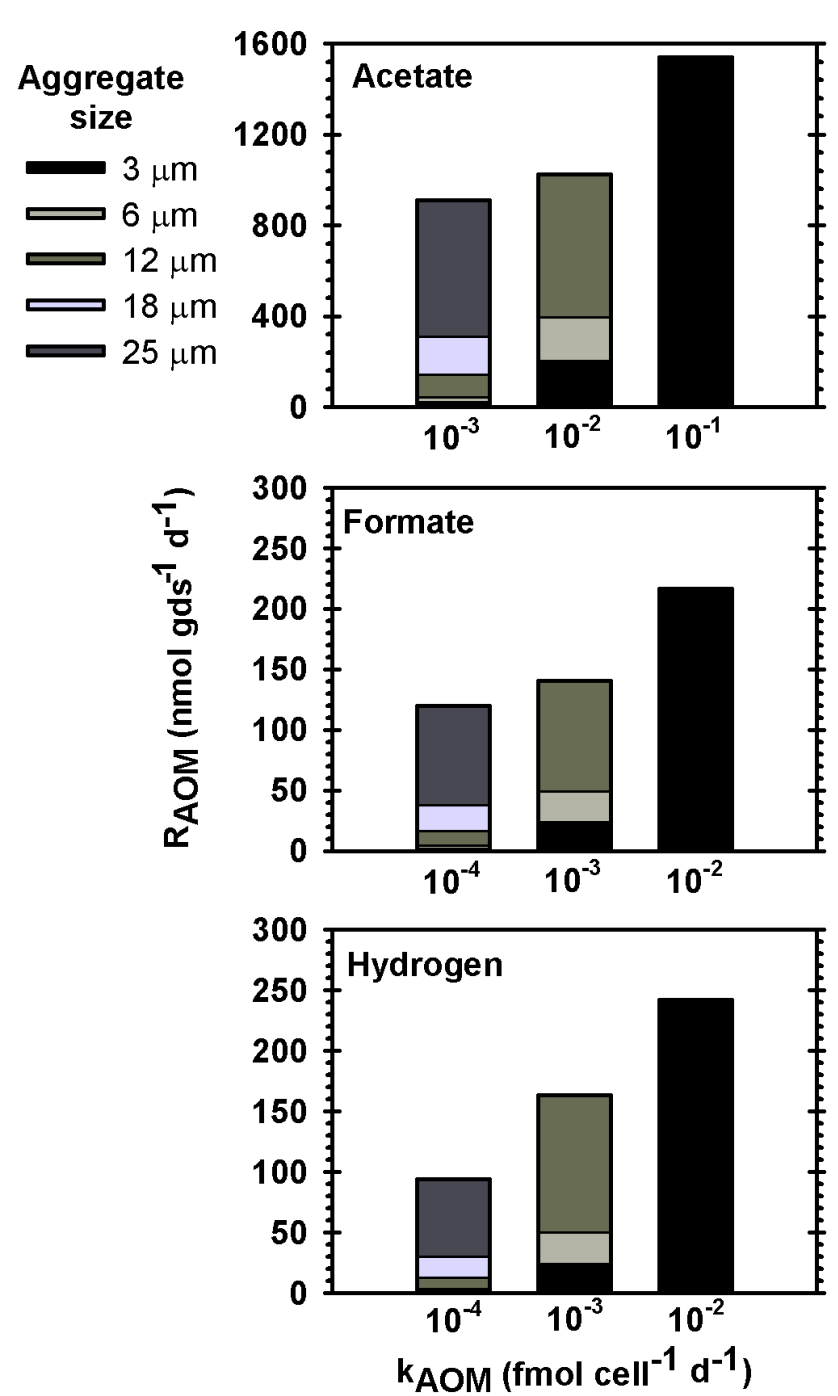

Fig. 4. Maximum bulk rates of AOM at different cell specific rates of AOM for each intermediate when the boundary methane concentration is $19 \mathrm{mM}$, the $m \Delta G_{\mathrm{ATP}}$ is $1 \mathrm{~kJ} \mathrm{~mol}^{-1}$ and the $K m \mathrm{EX}$ is $100 \mathrm{nM}$. $k_{\mathrm{SR}}$ is ten times higher than $k_{\mathrm{AOM}}$ for each simulation, which roughly corresponds to the optimal rate parameters. Note difference in $\mathrm{y}$-axes between panels, all of which express the bulk rate of AOM in nmol gds ${ }^{-1} \mathrm{~d}^{-1}$. Also note difference in values for $\mathrm{x}$ axis between panels. Bar stacks show cumulative bulk rate of AOM contributed by each aggregate size class based on the abundance data reported in the Nauhaus et al. (2007) experiment (see Table 5).

the cell specific AOM rates that lead to the highest bulk rate are $0.1 \mathrm{fmol} \mathrm{cell}^{-1} \mathrm{~d}^{-1}$ when acetate is the intermediate species and $0.01 \mathrm{fmolcell}^{-1} \mathrm{~d}^{-1}$ for formate and hydrogen (Fig. 4). However, only the $3 \mu \mathrm{m}$ sized aggregates can operate at these cell specific rates. The corresponding bulk AOM rates at this methane concentration are $1.5 \mu \mathrm{molgds}^{-1} \mathrm{~d}^{-1}$ for acetate, and $0.2 \mu \mathrm{molgds} \mathrm{gd}^{-1} \mathrm{~d}^{-1}$ for formate and hydrogen, which is much lower than the rate of activity measured in the experiment (approx. $230 \mu \mathrm{mol} \mathrm{gds}^{-1} \mathrm{~d}^{-1}$ ). 
With $100 \mathrm{mM}$ methane in the model environment, the maximum AOM bulk rate increases by about an order of magnitude to $12.5 \mu \mathrm{mol} \mathrm{gds}^{-1} \mathrm{~d}^{-1}$ with acetate as intermediate (data not shown), which still falls well short of the rates measured in the Nauhaus experiment. These results indicate that, at high methane concentration, acetate yields the highest possible rates of AOM, but under the experimental conditions the modeled rates are much lower than those observed.

\subsection{Can ANME "switch" metabolic modes to produce methane for energy generation?}

Experimental data allow for the possibility that some ANME perform methanogenesis under in situ conditions, although at a lower relative rate than that of AOM (Orcutt et al., 2005, 2008; Treude et al., 2007). Additional DNA and proteinbased analyses indicate that ANME possess enzymatic machinery to allow methane oxidation via a reverse methanogenesis pathway (Chistoserdova et al., 2005; Hallam et al., 2004; Krüger et al., 2003). To test whether environmental conditions and/or consortia dynamics may influence whether ANME perform methane oxidation and/or methanogenesis under in situ conditions, the model was modified to allow the ANME to "switch" metabolic modes from methanotrophy to methanogenesis based on their local environment. For instance, under conditions of concurrent low methane and high hydrogen concentration, methanogenesis may become energetically favorable, and perhaps the ANME can take advantage of this and operate in reverse. In the absence of experimental data it is assumed that the rate of methanogenesis Eq. (4) in reverse - proceeds at an intrinsic rate comparable to the one of methanotrophy and is also subject to thermodynamic constraints:

$R_{\mathrm{MG}}=k_{\mathrm{AOM}} B_{\mathrm{ANME}} F_{T-\mathrm{MG}}$

where $F_{T-\mathrm{MG}}$ is defined by Eq. (8) with $f_{X}=-f_{\mathrm{AOM}}$.

Regardless of the exchangeable species considered, under no gradient conditions at the domain boundary (i.e. when the consortia controls the concentration of the exchangeable species in the environment), the exchangeable species concentration within the consortia never reaches a high enough steady state value to make methanogenesis energetically favorable, regardless of aggregate size in the entire range considered ( $3 \mu \mathrm{m}<r_{\mathrm{agg}}<25 \mu \mathrm{m}$; data not shown). At high cell specific AOM values, AOM is basically shut down because of exchangeable species production, but concentrations never build up enough to cause a switch to methanogenesis.

In contrast, when the exchangeable species are forced to be at a certain concentration at the domain boundary, reflecting outside sources of the exchangeable species that are not modeled explicitly, the exchangeable species concentration in the AOM zone can reach values sufficiently high for reverse methanotrophy to become energetically feasible (Fig. 5). For example, at environmental hydrogen concentrations typical of AOM zones $(<5 \mathrm{nM})$, methanogenesis is not favorable regardless of the corresponding rate of SR; conditions are favorable for AOM, as long as $k_{\mathrm{AOM}}<0.1 \mathrm{fmol} \mathrm{cell}^{-1} \mathrm{~d}^{-1}$, above which the zone of activity $\left(F_{T-\mathrm{AOM}}>0\right)$ is smaller than the diameter of an ANME cell and therefore considered unrealistic (not shown). When the outside hydrogen concentration is $10-50 \mathrm{nM}$, a level more typical for deeper methanogenic sedimentary zones or possible in highly reduced fluids, the steady state hydrogen concentration within the consortia is high enough to permit methanogenesis when the corresponding rate of SR is low, though rapid $\mathrm{H}_{2}$ consumption (high $k_{\mathrm{SR}}$ ) can still favor AOM. At even higher environmental hydrogen concentrations (greater than $100 \mathrm{nM}$ ), conditions are never favorable for AOM regardless of the speed of SR.

These trends are similar when acetate and formate are considered as the exchangeable species, although the specific concentrations leading to the trends vary slightly. For example, with acetate, AOM is always favorable until the concentration of the exchangeable species in the environment exceeds $25 \mathrm{nM}$; at concentrations greater than $100 \mathrm{nM}$, AOM never becomes favorable. AOM from formate starts to become limited when the formate concentration in the environment is forced to be $25 \mathrm{nM}$, and formate levels of $300 \mathrm{nM}$ or higher are required to make AOM never favorable. Notably, at no instance are methanogenesis and methanotrophy observed simultaneously within the ANME core. However, if EX concentrations in the environment flucuate temporally and vary by about an order of magnitude, a change from methane oxidation to methanogenesis cannot be ruled out based on the model results (transition from 25 to $150 \mathrm{nM}$ acetate, 10 to $50 \mathrm{nM}$ formate and 1 to $10 \mathrm{nM} \mathrm{H}_{2}$, respectively, at $k_{\mathrm{SR}}=0.05 \mathrm{fmol} \mathrm{cell}^{-1} \mathrm{~d}^{-1}$; Fig. 5).

\section{Conclusions}

Model simulations indicate that all investigated compounds - acetate, formate, and hydrogen - have the potential to sustain a syntrophic AOM/SR relationship under a range of methane concentrations and with various assumed thresholds for free energy. However, none of the three potential intermediate compounds was found to generate modeled bulk rates of AOM that compared to an experimental observation (Nauhaus et al., 2007). Examining the impact of poorly constrained parameters, including transport coefficients and the effect of chemical speciation revealed that these factors are unlikely to sufficiently alter the rate of AOM to a large enough degree to substantially change this finding. A number of factors could be invoked that facilitate higher in situ AOM rates, including intrinsic variations in cell specific rates across consortia sizes or substantial modification of the local chemical environment through active cross-membrane transport (e.g. proton pumps; spatial $\mathrm{pH}$ variations impact both formate and hydrogen, but less so acetate; Table 1). 
Table 5. Consortia size and abundance measured in ANME/SRB aggregates (agg.) enriched from Hydrate Ridge sediment at the beginning (Beg.) and end of the experiment (from Nauhaus et al., 2007). OD=outer diameter.

\begin{tabular}{lccccccccc}
\hline$\mu$ m OD & \# ANME agg. $^{-1}$ & \multicolumn{2}{c}{$10^{6}$ agg. gds $^{-1}$} & \multicolumn{2}{c}{$\%$ aggregates } & \multicolumn{2}{c}{ cells gds $^{-1}$} & \multicolumn{2}{c}{$\%$ cells } \\
& & Beg. & End & Beg. & End & Beg. & End & Beg. & End \\
\hline 3 & 63 & 41 & 437 & 75 & 76 & $2.6 \times 10^{9}$ & $2.8 \times 10^{10}$ & 3 & 2 \\
6 & 504 & 8 & 58 & 15 & 10 & $4.2 \times 10^{9}$ & $2.9 \times 10^{10}$ & 5 & 2 \\
12 & 4034 & 3 & 33 & 5 & 6 & $1.2 \times 10^{10}$ & $1.3 \times 10^{11}$ & 13 & 9 \\
18 & 13615 & 1.2 & 18 & 2 & 3 & $1.7 \times 10^{10}$ & $2.5 \times 10^{11}$ & 18 & 17 \\
25 & 38094 & 1.5 & 26 & 3 & 5 & $5.6 \times 10^{10}$ & $9.9 \times 10^{11}$ & 61 & 69 \\
\hline
\end{tabular}

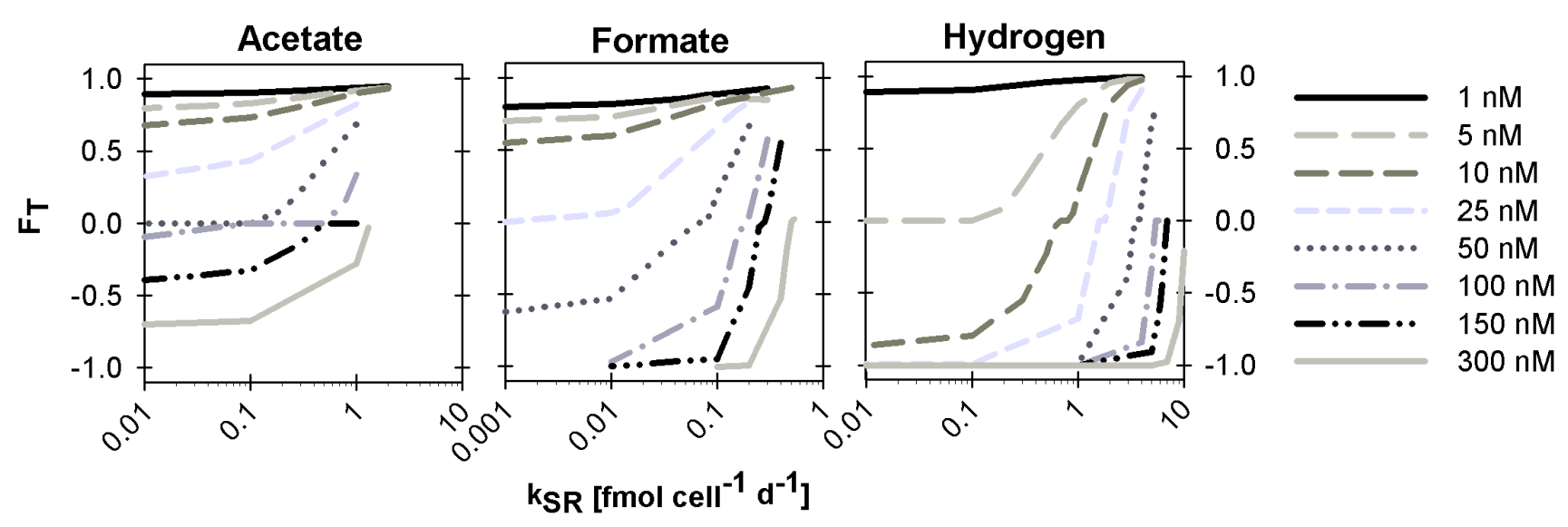

Fig. 5. Volume averaged values of $F_{T}$ for a $3 \mu \mathrm{m}$ OD consortia with fixed environmental concentrations of the intermediate species (1$300 \mathrm{nM}$, as indicated in the legend). For all simulations, methane in the environment was assumed to be $19 \mathrm{mM}, m \Delta G_{\mathrm{ATP}}=1 \mathrm{~kJ} \mathrm{~mol}{ }^{-1}$, $k_{\mathrm{AOM}}=0.01 \mathrm{fmol} \mathrm{cell}^{-1} \mathrm{~d}^{-1}$, and $K m \mathrm{EX}=100 \mathrm{nM}$. Cell specific rates of SR $\left(k_{\mathrm{SR}}\right)$ are presented on x-axes (note scale differences between panels). $F_{T}$ varies between -1 and 0 when $\Delta G_{\text {methanogenesis }}\left(=-\Delta G_{\mathrm{AOM}}\right)$ is more negative than the minimum energy quantum required for ATP production and methanogenesis becomes active. In an intermediate range, both forward and backward reaction are not feasible and the archaea are considered inactive $\left(F_{T-\mathrm{MG}}=F_{T-\mathrm{AOM}}=0\right)$, while at more negative $\Delta G_{\mathrm{AOM}}$, methane gets oxidized, indicated by $F_{T}$ ranging from 0 to 1 (Eq. 8). Right-hand end of lines indicate conditions where the zone of possible sulfate reduction collapses to zone smaller than a cell diameter.

Alternatively, a more complex geometry than the one considered may facilitate contact between the syntrophic partners, or other physiological adaptations, including a network of nanowire-like structures (Reguera et al., 2006), that allows for a more efficient exchange between ANME and SRBs may alleviate the identified thermodynamic constraints. Our mechanistic, process-based model analysis and comparison to rates measured in laboratory incubation shows that all three factors - reaction kinetics, transport intensities and energetic considerations - decisively impact the overall rate of methane consumption. The potential for significant spatial variability in the availability of the exchangeable species is predicted even over distances $<10 \mu \mathrm{m}$, a finding to be corroborated e.g. by mapping regions of active growth and uptake of compounds with coupled FISH-SIMS. Balancing of transport and different reaction processes leaves room for a variety of mechanisms for the interaction between the consortium partners - including pathway reversal under fluctuating environmental concentrations of the exchangeable species, and alternatives to the three intermediates investigated here - and metabolic plasticity may prevail even in methane oxidizing consortia that live in environments with little excess energy.

Acknowledgements. We would like to thank Antje Boetius and Katja Nauhaus for sharing raw experiment data on consortia dynamics, Samantha Joye for helpful discussion, and Andy Dale, Bernie Boudreau and Mark Alperin for useful comments that significantly improved the manuscript. This work was supported by a National Science Foundation Graduate Research Fellowship to 
B. Orcutt while at UGA and a fellowship from the Hanse Institute for Advanced Studies to C. Meile that provided hospitality and financial support in Delmenhorst, Germany. C. Meile also acknowledges support by the Office of Science of the United States Department of Energy (DE-FG02-05ER25676).

Edited by: J. Middelburg

\section{References}

Barnes, R. O. and Goldberg, E. D.: Methane production and consumption in anaerobic marine sediments, Geology, 4, 297-300, 1976.

Boetius, A., Ravenschlag, K., Schubert, C. J., Rickert, D., Widdel, F., Gieseke, A., Amann, R., Jørgensen, B. B., Witte, U., and Pfannkuche, O.: A marine microbial consortium apparently mediating anaerobic oxidation of methane, Nature, 407, 623-626, 2000.

Boudreau, B. P.: Diagenetic models and their implementation, Springer-Verlag, 414 pp., 1997.

Chistoserdova, L., Vorholt, J. A., and Lidstrom, M. E.:

A genomic view of methane oxidation by aerobic bacteria and anaerobic archaea, Genome Biology, 6(208), doi:10.1186/gb2005-6-2-208, available at: http://genomebiology.com/2005/6/2/ 208, 2005.

Dale, A. W., Regnier, P., and van Cappellen, P.: Bioenergetic controls on anaerobic oxidation of methane (AOM) in coastal sediments: A theoretical analysis, Am. J. Sci., 306, 246-294, 2006.

Devol, A. H., Anderson, J. J., Kuivila, K., and Murrary, J. W.: A model for coupled sulfate reduction and methane oxidation in the sediments of Saanich Inlet, Geochim. Cosmochim. Ac., 48, 993-1004, 1984.

Deppenmeier, U.: Redox-driven proton translocation in methanogenic Archaea, Cell. Mol. Life Sci., 59, 1513-1533, 2002.

Finke, N.:

The role of volatile fatty acids and hydrogen in the degradation of organic matter in marine sediments, Ph.D. thesis, University of Bremen, 2003.

Girguis, P. R., Cozen, A. E., and DeLong, E. F.: Growth and population dynamics of anaerobic methane-oxidizing archaea and sulfate-reducing bacteria in a continuous-flow bioreactor, Appl. Environ. Microb., 71(7), 3725-3733, 2005.

Girguis, P. R., Orphan, V. J., Hallam, S. J., and DeLong, E. F.: Growth and methane oxidation rates of anaerobic methanotrophic archaea in a continuous-flow bioreactor, Appl. Environ. Microb., 69(9), 5472-5482, 2003.

Hallam, S. J., Girguis, P. R., Preston, C. M., Richardson, P. M., and DeLong, E. F.: Identification of methyl coenzyme M reductase A (mcrA) genes associated with methane-oxidizing archaea, Appl. Environ. Microb., 69(9), 5483-5491, 2003.

Hallam, S. J., Putnam, N., Preston, C. M., Detter, J. C., Rokhsar, D., Richardson, P. M., and DeLong, E. F.: Reverse methanogenesis: Testing the hypothesis with environmental genomics, Science, 305, 1457-1462, 2004.

Hinrichs, K.-U., Hayes, J. M., Sylva, S. P., Brewer, P. G., and DeLong, E. F.: Methane-consuming archaebacteria in marine sediments, Nature, 398, 802-805, 1999.
Hoehler, T. M., Alperin, M. J., Albert, D. B., and Martens, C. S.: Field and laboratory studies of methane oxidation in an anoxic marine sediment - evidence for a methanogen-sulfate reducer consortium, Global Biogeochem. Cy., 8, 451-463, 1994.

Hoehler, T. M., Alperin, M. J., Albert, D. B., and Martens, C. S.: Thermodynamic control on hydrogen concentrations in anoxic sediments, Geochim. Cosmochim. Ac., 62, 1745-1756, 1998.

Iversen, N. and Jørgensen, B. B.: Anaerobic methane oxidation rates at the sulfate-methane transition in marine sediments from Kattegat and Skagerrak (Denmark), Limnol. Oceanogr., 30, 944955, 1985.

Jackson, B. E. and McInerney, M. J.: Anaerobic microbial metabolism can proceed close to thermodynamic limits, Nature, 415, 454-456, 2002.

Jin, Q. and Bethke, C. M.: A new rate law describing microbial respiration, Appl. Environ. Microb., 69(4), 2340-2348, 2003.

Jin, Q. and Bethke, C. M.: The thermodynamics and kinetics of microbial metabolism, Am. J. Sci., 307, 643-677, 2007.

Knittel, K., Boetius, A., Lemke, A., Eilers, H., Lochte, K., Pfannkuche, O., and Linke, P.: Activity, distribution, and diversity of sulfate reducers and other bacteria in sediments above gas hydrate (Cascadia Margin, Oregon), Geomicrobiol. J., 20, 269294, 2003.

Knittel, K., Lösekann, T., Boetius, A., Kort, R., and Amann, R.: Diversity and Distribution of Methanotrophic Archaea at Cold Seeps, Appl. Environ. Microb., 71(1), 467-479, 2005.

Krüger, M., Meyerdiecks, A., Glockner, F. O., Amann, R., Widdel, F., Kube, M., Reinhardt, R., Kahnt, R., Bocher, R., Thauer, R. K., and Shima, S.: A conspicuous nickel protein in microbial mats that oxidize methane anaerobically, Nature, 426, 878-881, 2003.

Martin, I., Dozin, B., Quarto, R., Cancedda, R., and Beltrame, F.: Computer-based technique for cell aggregation analysis and cell aggregation in in vitro chondrogenesis, Cytometry, 28, 141-146, 1997.

Nauhaus, K., Albrecht, M., Elvert, M., Boetius, A., and Widdel, F.: In vitro cell growth of marine archaeal-bacterial consortia during anaerobic oxidation of methane, Environ. Microbiol., 9(1), 187196, 2007.

Nauhaus, K., Boetius, A., Krueger, M., and Widdel, F.: In vitro demonstration of anaerobic oxidation of methane coupled to sulfate reduction from a marine gas hydrate area, Environ. Microbiol., 4, 296-305, 2002.

Neretin, L., Abed, R. M. M., Schippers, A., Schubert, C., Kohls, K., and Kuypers, M. M. M.: Inorganic carbon fixation by sulfatereducing bacteria in the Black Sea water column, Environ. Microbiol., 9, 3019-3024, 2007.

Orcutt, B. N., Joye, S. B., Boetius, A., Elvert, M., and Samarkin, V. A.: Molecular biogeochemistry of sulfate reduction, methanogenesis and the anaerobic oxidation of methane at Gulf of Mexico cold seeps, Geochim. Cosmochim. Ac., 69(17), 4267-4281, 2005.

Orcutt, B. N., Samarkin, V., Boetius, A., and Joye, S. B.: On the relationship between methane production and oxidation by anaerobic methanotrophic communities from cold seeps of the Gulf of Mexico, Environ. Microbiol., 10(5), 1108-1117, doi:10.1111/j.1462-2920.2007.01526.x, 2008.

Orphan, V. J., Hinrichs, K.-U., Ussler III, W., Paull, C. K., Taylor, L. T., Sylva, S. P., Hayes, J. M., and DeLong, E. F.: Comparative analysis of methane-oxidizing archaea and sulfate-reducing bac- 
teria in anoxic marine sediments, Appl. Environ. Microb., 67(4), 1922-1934, 2001.

Orphan, V. J., House, C. H., Hinrichs, K.-U., McKeegan, K. D., and DeLong, E. F.: Multiple archaeal groups mediate methane oxidation in anoxic cold seep sediments, P. Natl. Acad. Sci. USA, 99, 7663-7668, 2002.

Reeburgh, W. S.: Methane consumption in Cariaco Trench waters and sediments, Earth Planet. Sc. Lett., 28, 337-344, 1976.

Reguera, G., Nevin, K. P., Nicoll, J. S., Covalla, S. F., Woodard, T. L., and Lovley, D. R.: Biofilm and nanowire production leads to increased current in Geobacter sulfurreducens fuel cells, Appl. Environ. Microb., 72(11), 7345-7348, 2006.

Schink, B.: Energetics of syntrophic cooperation in methanotrophic degradation, Microbial Molecular Biology Review, 61, 262-280, 1997.

Schulz, H. D.: Quanitification of Early Diagenesis: Dissolved Constituents in Marine Pore Water, in: Marine Geochemistry, edited by: Schulz, H. D. and Zabel, M., Springer, 87-128, 2000.

Sørensen, K. B., Finster, K., and Ramsing, N. B.: Thermodynamic and kinetic requirements in anaerobic methane oxidizing consortia exclude hydrogen, actetate, and methanol as possible electron shuttles, Microb. Ecol., 42, 1-10, 2001.

Stewart, P. S.: Diffusion in biofilms, J. Bacteriol., 185(5), 14851491, 2003.
Strous, M. and Jetten, M. S. M.: Anaerobic oxidation of methane and ammonium, Annu. Rev. Microbiol., 58, 99-117, 2004.

Stumm, W. and Morgan, J. J.: Aquatic Chemistry: An Introduction Emphasizing Chemical Equilibria in Natural Waters, John Wiley and Sons, 1022 pp., 1981.

Thauer, R. K., Jungermann, K., and Decker, K.: Energy conservation in chemotrophic anaerobic bacteria, Microbiol. Rev., 41, 100-180, 1977.

Treude, T., Orphan, V. J., Knittel, K., Gieseke, A., House, C. H., and Boetius, A.: Consumption of methane and $\mathrm{CO} 2$ by methanotrophic microbial mats from gas seeps of the anoxic Black Sea, Appl. Environ. Microb., 73, 2271-2283, 2007.

Valentine, D. L. and Reeburgh, W. S.: New perspectives on anaerobic methane oxidation, Environ. Microbiol., 2(5), 477-484, 2000.

Valentine, D. L.: Biogeochemistry and microbial ecology of methane oxidation in anoxic environments: a review, Anton. Leeuw. Int. J. G., 81, 271-281, 2002.

Wieland, A., de Beer, D., Damgaard, L. R., Kühl, M., and van Dusschoten, D.: Fine-scale measurement of diffusivity in a microbial mat with nuclear magnetic resonance imaging, Limnol. Oceanogr., 46(2), 248-259, 2001. 